\title{
Itinerari geoambiental pel litoral de l'àrea metropolitana de Barcelona
}

\author{
Concepció Rodon Galceran \\ cupirodon@gmail.com
}

Itinerari dissenyat com a suggeriment de sortida $i$ treball al litoral, una proposta oberta d'itinerari per una zona del litoral propera a l'àrea metropolitana. Permet seguir una via contínua utilitzant la línea de costa, integrant infraestructures viàries, passejos i camins ja existents.

Paraules clau: educació ambiental, batxillerat, medi litoral-marí, recursos, itinerari

\section{Introducció}

El paisatge natural s'artificialitza de mica en mica per la creixent presència humana i deixa un ventall de paisatges amb diferents graus d'antropització segons les actuacions i la gestió de la zona. Sovint les sortides es plantegen com una observació en un paisatge natural amb molt d'interès biològic i es tendeix a allunyar-se de les zones més densament poblades, com si aquell indret fos idíl-lic i servís de model. Però a tocar de les ciutats litorals amb més densitat de població tenim un paisatge també amb interès biològic i sobretot mediambiental que, tot i ser tan proper, es té poc en compte.
Les zones més densament poblades es situen a prop del litoral; aquesta situació que trobem a Catalunya es repeteix al llarg de la Mediterrània (fig. 1).

L'itinerari és una proposta on s'exposen algunes possibilitats d'estudi, però l'aplicació és oberta a qualsevol combinació i concreció que s'adapti millor a les necessitats de cada grup. No es tracta d'una activitat dirigida, es tracta de suggeriments per la recerca dels estudiants sobre temàtiques mediambientals relacionades amb el litoral-marí. Plantejar qüestions als alumnes i que ells dissenyin la recerca, experimentin les seves hipòtesis de treball sobre el terreny, veure com és, per què es així, com podria ser i sobretot com volem que sigui.

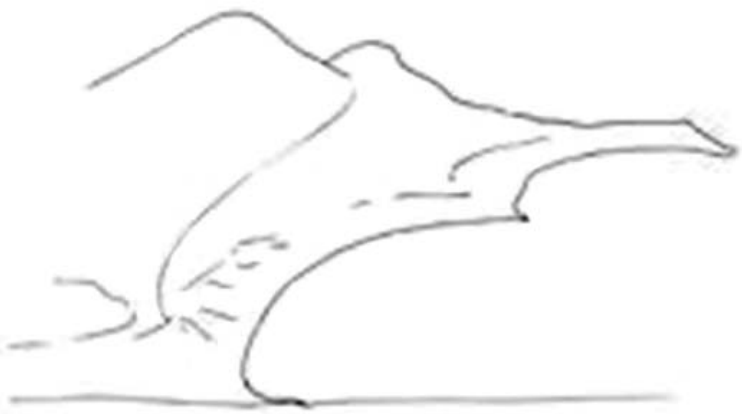

Paisatge natural

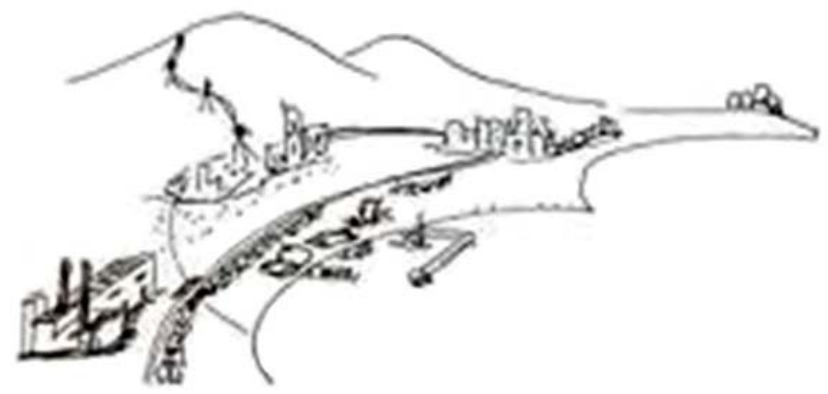

Paisatye alterat

Figura 1. Artificialització del paisatge. 


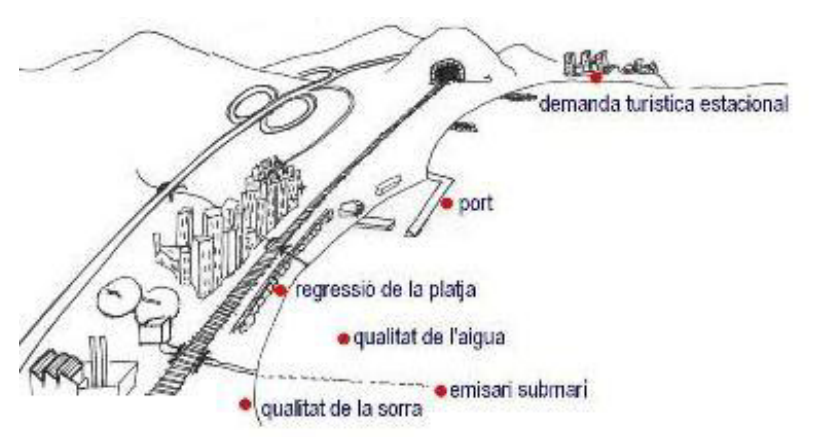

Figura 2. Problemàtica litoral.

La gestió de les costes ha de ser global i ha d'incorporar el concepte de desenvolupament sostenible. Ha de gestionar problemàtiques comunes al llarg del litoral com:

- L'emissari submarí que aboca aigües negres prop d'una platja pública.

- El port esportiu que malmet el paisatge, les comunitats vives de la zona i que desvia corrents i sorres.

- L'ocupació exagerada del litoral per obra viva i la modificació de la línia de costa per actuacions d'enginyeria.

- La pesca que sobreexplota caladors profunds i malmet herbeis costaners, on és il.legal passar les xarxes.

- El consum d'espai litoral, de dunes i d'aiguamolls per part de la indústria turística i del lleure.

- L'ús immoderat d'aigua, que provoca l'exhauriment dels freàtics costaners i la intrusió d'aigua de mar i llur salinització.

- La contaminació procedent de l'agricultura, la indústria, la mineria i l'urbanisme descontrolat (fig. 2).

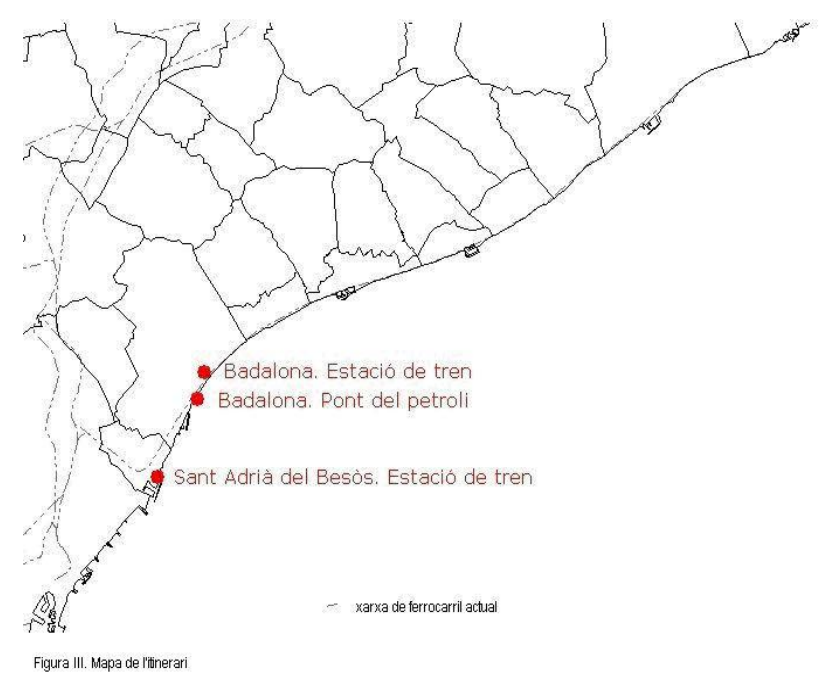

Figura 3. Mapa de l'itinerari.

\section{Itinerari geoambiental}

L'itinerari consisteix en diferents parades al llarg d'una zona de la costa. Aquest trajecte es pot realitzar amb bicicleta o patins, amb tren i autobús o amb autocar. L'itinerari transcorre paral-lel a la costa i es pot fer en qualsevol mitjà de transport apte per fer un transsecte doble, d'anada i de tornada, amb un recorregut ràpid en temps i ampli en distància. La línia paral.lela a la costa és el punt de partida per l'itinerari. La zona d'estudi es concreta al municipi de Sant Adrià del Besòs i Badalona, però pot ser ampliat o extrapolat a altres indrets de la costa (fig. 3).

El punt de partida és l'estació de tren de St. Adrià del Besòs. A prop tenim el tramvia, una estació de bicing i, si passem el pas soterrat a l'altra banda de la via del tren, la línia d'autobús.

Cal accedir a la platja i des d'allí es poden realitzar diferents treballs sobre una zona molt alterada de l'àrea metropolitana de Barcelona. En aquest punt es proposen dues línies de treball: el retrocés de la línia de la costa i la qualitat de la sorra de la platja. El color, la granulometria i la disposició de la sorra ens poden donar informació de la seva procedència i de les vies d'aportació de la sorra en aquesta zona. La transformació industrial produïda ara fa unes dècades ens pot donar informació del seu estat actual i de la seva evolució en el temps.

L'itinerari passa pel port de Badalona on es pot observar la diferent sedimentació a un cantó i a l'altre del mateix port. Aquest fenomen és observable també en altres ports molt propers: EI Masnou i Premià de Mar. Aquesta observació es pot fer aprofitant el tren com a transport; una altra possibilitat és utilitzar mapes on es tingui una visió global de la zona (fig. 4).

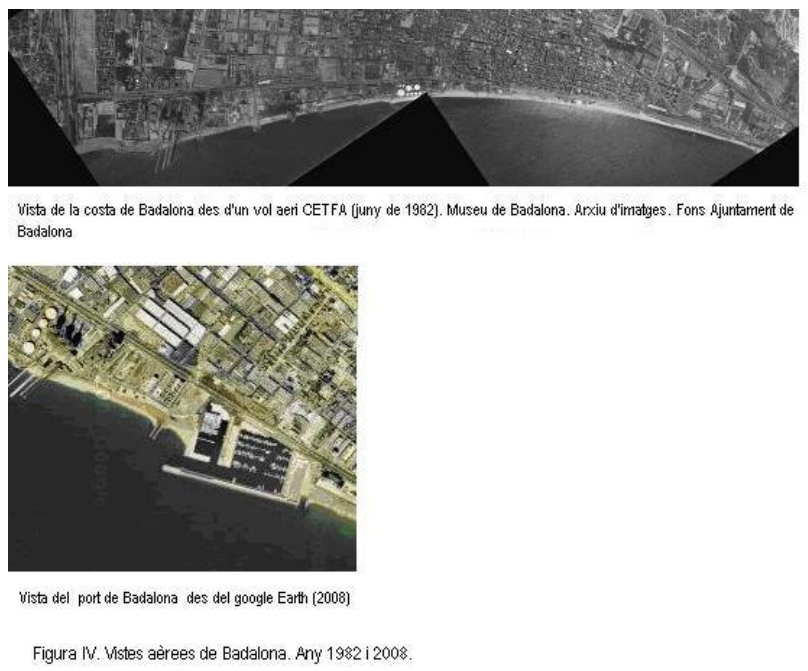

Figura 4. Vistes aèries de Badalona, 1982 i 2008. 
Els espigons i les esculleres protegeixen la costa frenant la força erosiva de les onades sobretot en els temporals. D'altres infraestructures paralleles a la costa com els col.lectors queden també protegides per una segona línia d'escullera.

Un cop passat el port de Badalona pararem davant del pont del petroli, una estructura singular que està en procés de rehabilitació per transformarse en un punt d'interès científic. En aquest punt es proposen dues línies més de treball: estructures de defensa contra els temporals i el pont del petroli. Aquesta estructura singular oberta al públic com un passeig marítim endinsat al mar, és també una estació meteorològica i oceanogràfica. Les dades poden ser consultades en temps real a la pàgina web.

L'escola del mar de Badalona és el centre d'educació ambiental que es troba en la zona on es proposa l'itinerari i també ofereix diverses activitats destinades al coneixement i l'estudi del medi marí.

Aquest article resumeix l'itinerari geoambiental dins d'un treball més extens que podeu consultar a http://www.xtec.cat/ crodon1/

\section{Referències}

ACEBILLO, J., FOLCH, R. (2000). Atles ambiental de l'Àrea de Barcelona: Balanç de recursos $i$ problemes. Barcelona: Ariel Ciencia.
Tren, Renfe (horaris i recorregut) [Consulta: 8 novembre 2010] http://www.renfe.com/cercanias/barcelona/index horarios.html

Autobús BD7 (horaris i recorregut) [Consulta: 8 novembre 2010] http://www.tusgsal.net/cat/diabus.htm

Bicing (punts i tarifes) [Consulta: 8 novembre 2010] http://www.bicing.com/

Tramvia, Trambesòs (horaris i recorregut) [Consulta: 8 novembre 2010] http://www.trambcn.com/buscador besos.php?i dioma $=$ cat\&PHPSESSID=a7ad06601a9178936 08ef760b5cee814

Àrea del Transport Metropolità de Barcelona. [Consulta: 8 novembre 2010] http://www.atm.cat/indexcat.htm

Pont del petroli de Badalona.[Consulta: 8 novembre 2010] http://www.pontdelpetroli.org

Escola del Mar de Badalona.[Consulta: 8 novembre 2010]

http://www.badalona.cat/aj-badalona/mediambient/ca/escola-mar/oferta-educativa.html

Recerca realitzada gràcies a una llicència d'estudis retribuïda concedida pel Departament d'Educació de la Generalitat de Catalunya (DOGC núm.: 4968 de 14/09/2007). 